\title{
Workshops for subject-specific teachers' training: A case study for teaching cancer biology
}

\author{
Lauren Pecorino, Richard Grose, Pinar Uysal-Onganer \\ University of Greenwich, Queen Mary University of London, University of Westminster
}

This work was supported by The Biochemical Society.

\begin{abstract}
Teachers' training in higher education institutions widely serves general purposes. However, recent dialogues and research highlight the importance of teachers' deep understanding of the material being taught and the ways students think about the content as critical components of great teaching. The authors explored the novelty of providing a one-day workshop entitled, 'Effective strategies for teaching cancer biology'. The Biochemical Society supported the event and marketed it throughout the UK - not with any targeted level of university teaching experience, and aAttendees therefore ranged from those who had never taught to those at the level of Senior Fellow of the Higher Education Academy. The day included various short talks, the sharing of good practice and the opportunity to experience a demonstration lesson as a student. Twelve out of thirteen who provided feedback had not received previous subject-specific teacher-training. Half of the attendees gave feedback with the highest score out of five, having found the event 'very valuable'. This experience suggests that subject-specific training may be beneficial and applicable to other subject areas.
\end{abstract}

Keywords: Cancer Biology, university teaching, subject-specific teachers' training, Higher Education Academy.

\section{Introduction}

Most teachers' training is presented for general purposes, including the importance of student engagement, types of feedback and variation in types of assessment. However, recent dialogues and research emphasise that all teaching skills are underpinned by knowledge of the material being taught. The Sutton Trust Report (2014) highlights six components of great teaching suggested by research, stating that there is strong evidence that (pedagogical) content knowledge has positive impact on student outcomes. Developing teachers' knowledge of what they are teaching is central. One blogger comments: " ...it should not come as any great surprise that the greatest impact on student outcomes is likely to come from a teacher who knows their subject well and how to teach the nuances and challenges of it to different learners at different stages of their development. The heavy focus on developing 'generic' skills was wrong and imbalanced." (Stock, 2016). Different subjects must be taught in different ways (Rowland et al., 1998). Michael Fordham (2014) takes this concept further and quantitates this concept in his blog: ' $90 \%$ of teacher training should be subject-specific.' 
The authors organised and delivered a one-day, subject-specific teacher training workshop, the aim of which was to provide cancer biology-specific teachers' training. The work was supported by a training grant from the Biochemical Society.

One of the key aims in higher education (HE) is to create an interactive environment. Learning is a reflexive activity (Kolb, 1984), grounded in interaction and dialogue, imbued with personal connection, with the aim of developing a partnership with students (Flint, 2015). Through discussion and demonstration, the workshop addressed various strategies for creating such a learning environment.

Using a textbook for final-year teaching is sometimes a point of contention. Though some lecturers may be averse to the use of a textbook for final-year teaching, we chose to present a widely-used textbook for undergraduates (Pecorino, 2016), to illustrate that there are advantages in the judicious application of a required text for a university course, especially for structuring specific strategies for learning.

\section{Accreditation}

The Higher Education Academy (HEA) recognised that the workshop covered specific points of the Higher Education Teaching Framework. These included: A2 (Teach and support learning), A3 (Assess and give feedback to learners), K1 (Knowledge of subject area), K2 (Appropriate methods of teaching and learning in subject area and level) and V3 (Use evidence-informed approaches).

\section{Itinerary}

The Introduction to the course presented course aims and learning outcomes.

\section{Sharing best practice and identifying motivational forces for learning}

An open discussion explored the question 'When does learning take place?' The conversation led to conclusions similar to those reported in the literature: that is, learning takes place when the student is engaged in a task (Fry, 2008), when the student is being tested (Boud, 1986) and when the student is motivated to learn (Biggs and Tang, 2011). An examination of a recommended textbook and its useful features ensued. The author of the noted textbook had identified a motivational force for learning cancer biology: the learning of basic cancer biology can be applied to the development of novel therapeutics. She structured the book to link these two concepts in each chapter, a change from the more traditional way of teaching, in which treatments are covered separately and usually at the end of a course. Students were compelled by this novel approach to learn basic biology in order to grasp how new drugs are being developed today. The textbook also contains features such as 'How do we know that?' so that experimental approaches and experimental data underlying the facts can be investigated.

\section{Approaches for particular student audiences}

Several subject-relevant talks followed, including how to teach statistics non-technically, given by Dr Shah-Jalal (Barts Cancer Institute), and how to teach cancer biology to medical students in a week presented by Richard Grose. Since increases in life expectancy, coupled with improved detection and treatment of cancer, mean that there will be a growing demand 
for oncologists (Erikson et al., 2007), it is critical that medical students are engaged by cancer biology lectures. Grose discussed how an intensive week of cancer teaching - using the classic 'Hallmarks of Cancer' (Hanahan and Weinberg, 2011) as a fundamental publication reinforced by lectures from experts in research and clinical aspects of cancer could engage and enthuse students. In such an intensive week, fundamental principles, backed up by case studies detailing the practical delivery of cancer therapy ensures that students benefit from evidence-based teaching (Gaffan et al., 2006), alongside a problemsolving learning approach that encourages students to explore clinical scenarios in a groupbased setting (Neville, 2009). One such scenario uses BRAF mutant melanoma as an example - allowing students to understand the disease from the molecular level and link this to an appreciation of the efficacy and limitations of targeted therapies, using striking imagery of Vemurafenib resistance (Wagle et al., 2011). This foundation in cancer biology and treatment could then be built upon during student-selected components throughout the undergraduate course. These provide an excellent opportunity for students to guide their own learning, as recommended in the GMC guidelines - 'Promoting Excellence: standards for medical education and learning' (2016).

\section{Experiential learning}

Marcus Gibson, Director of Gibson Index and former Financial Times writer, broached the topic of apprenticeships and placements with his talk 'Companies involved in cancer research across the UK'. Gibson Index is a database of small and medium UK enterprises (SMEs) and has been used by several universities - and for several disciplines - to facilitate student apprenticeships and placements.

\section{Advantages and challenges of various types of assessment and feedback}

Workshop participants shared experiences of using such common assessment types as critical reviews, presentations and projects and viewed some distributed examples of student work. The ability to review a primary paper critically is a fundamental skill for cancer biologists, yet some challenges exist in designing assessments to test this skill. Perhaps the biggest challenge is shifting students' focus from a mere reading of the 'results' section to a careful evaluation of the data. Instructions such as 'critically review this paper' do not provide sufficient direction. One solution is to ask students to read a paper critically and then to test them by means of specific test questions pertaining to the data: a) Which figure demonstrates that? b) In Figure $X$, what is the control? c) How much of an increase in protein levels is shown by the data in Figure $Y$ ? d) Is the experiment shown in Figure $Z$ direct or indirect evidence for $\mathrm{X}$ ?

Presentations are a common method of assessment. Student partnership is further developed in teaching by involving students to peer-mark group presentations. We have always appreciated the value of assigning group talks but felt that the attention of the student audience sometimes drifted. The solution came from Race (2009, p.35): "If they [the students] are evaluating each presentation using an agreed set of criteria, they tend to engage themselves more fully..." Creating Wiki pages, another assessment type, encourages teamwork for building an online repository and portfolio.

Designing independent final-year projects can be problematic for large cohorts with limited resources. The workshop discussed one possible suggestion: The Human Genome Project. 
Here, each student, selects a gene of interest with a known mutation linked to cancer and uses polymerase chain reaction (PCR) and sequence analysis for their investigation. Students use bioinformatics to locate their mutation of interest, design primers and test primers in silico. Primer synthesis is outsourced. PCR is then used to amplify a fragment of DNA from a commercial source of DNA (e.g. human placental). Hybridisation temperature optimisation is required. Students carry out isolation and quantification of PCR product before sending their DNA for off-campus sequencing. Sequence data are analysed further by bioinformatics. A 10,000-word written report is required and must include an introduction to the gene supported by primary literature and evidence demonstrating that the specific mutation is linked to cancer. It is expected that students provide a critical discussion of their data within the context of the literature.

\section{Teachers as students}

The attendees of the workshop took the places of students in a lecture demonstration given by Lauren Pecorino, the author of the noted textbook: 'The Molecular Biology of Cancer'. They then discussed some of the lecture's teaching elements, such as pre-learning activities, student participation, entering student space to give one-to-one feedback on a given task, use of diagrams to understand complex concepts of growth-signalling pathways and the development of therapeutics against molecular targets. The success of these strategies is evidenced in student feedback. For example, students welcome being given, on a regular basis, the task of reading a textbook chapter or review paper before a lecture. There was further discussion of role play and post-learning activities. For instance, role play may be profitably deployed towards the end of the course, after students have learned about many strategies used for drug development: You now work for Pfizer; design a drugdevelopment strategy to target one of the molecules involved in this newly-discovered signalling pathway. These exercises develop student self-efficacy - confidence in one's own ability to achieve intended results (Ritchie, 2015).

\section{E-learning and mobile applications, and other resources}

Pinar Uysal-Onganer presented specific e-learning resources she had trialled. Mobile learning has, since the 1990s, invaded the fields of HE, especially in medicine and healthcare. The early applications of mobile learning involved the delivery of courses:

uploading lectures and videos online. This approach mobilised learning outside the classroom. Mobile learning originates from online learning and has been enabled by the intersection of technological advancement and learner-centred pedagogy (Crompton 2013). Currently, projects within the HEA are investigating the importance and the limitations of mobile learning. Laurillard (2002) summarised the framework of effective use of learning technologies and promoted mobile learning, as it provides an environment to enable conversation, gives an opportunity to learners to build models for problem-solving and allows accessibility to all students. A more holistic approach to mobile learning was proposed by Koole (2009), who discussed three aspects: the learner, social interactions and new technological devices. According to this model, at least two different combinations of these aspects should be considered. The workshop reviewed all of them.

Mobile applications such as Poll Everywhere, NearPod, Kahoot!, Zeetings, and Padlet were discussed. Poll Everywhere is a platform that encourages student interaction and enhances student engagement. It also allows teachers to get instant feedback and to modify teaching 
strategies. Attendees had the opportunity to try these applications on provided iPads. There were demonstrations of how all participants in a class can access and collaborate, using a single webpage - for the discussion of a specific cancer topic or for the analysis of a specific data set. For example, a designed group activity allowed for exploration and discussion of potential therapeutic targets of a specific cancer-signalling pathway. Group results were then opened for whole-class discussion and compared to current clinical trials and approved therapies now in the clinic.

With virtual learning platforms such as Labster, the workshop demonstrated next-generation sequencing and there was discussion of applications to other commonly-used molecular biology techniques. A Virtual Pathology platform

(www.virtualpathology.leeds.ac.uk/teaching/collections) was noted as being a helpful resource for cancer pathology courses.

The use of a freely-available global cancer epidemiology website (http://globocan.iarc.fr) was demonstrated. It was noted that cross-cultural awareness and engagement could be highlighted by class activities using this resource. For example, individual students can be asked to present the top five cancers in a country of their choice. A discussion of geographical differences could underpin differences in cancer etiology. Moreover, educational videos can be obtained from the National Cancer Institute science education tool (www.science.education.nih.gov).

\section{Collaborative design of a lecture on a new topic in the field and recommendations for student engagement}

The attendees of the workshop were asked to design a lecture on the trending topic of cancer immunotherapies. Different suggestions were collated on a whiteboard.

The following is a summary of the discussion, which followed the completion of the attendees' task in designing a lecture on cancer immunotherapies. The discussion was divided into content for pre-learning, course delivery and post-learning and included activities for student engagement.

Pre-learning: It was agreed that pre-assigned reading of a textbook chapter or review was necessary. To ensure students engaged in the material, they could be asked to design multiple-choice questions based on the reading. Additional e-learning, such as a video, could be added. Students could also be asked to bring in items in the news to class for discussion.

Lecture delivery: Suggestions for the content during lecture delivery included a wide range of topics - from historical introductions, basics of immunology and comparisons of new immunotherapies with conventional chemotherapies, to the inclusion of a discussion of animal models (limited by the use of mice that were not immune-deficient), clinical aspects, methods of drug development and possibly the inclusion of ethics and costs. Delivery could include short videos and other online resources. Student engagement could include formative assessments that involve drawing cartoon diagrams summarising the molecular aspects of tumour-immune cell interaction. It was suggested that students should be encouraged to confer with classmates in their vicinity. Peer learning has been highlighted in the literature. Academic staff can enter student space at this time and visit individual students. Feedback to the entire class can then be given. Students can also be asked to 
think about how they would use this information to develop a new immunotherapy. They should be encouraged to think about strategies that they have already learned about and to apply this knowledge to this new application.

Post-learning: Students may be asked to draw concept maps / summary diagrams and answer critical questions. Websites such as www.Clinicaltrials.gov could be consulted to summarise and update information. Specific Ted Talks around the subject area were suggested to be a useful additional resource.

The workshop concluded with a summary and refreshments, the latter offering opportunity for further networking. Attendees received a copy of the noted textbook by Pecorino along with sample coursework questions and list of e-learning resources.

\section{Feedback}

Attendees were asked to provide online feedback for several days after the event. The feedback was administered by The Biochemical Society and included routine feedback questions, along with questions designed by the authors of this paper.

Twelve out of thirteen attendees who provided feedback had not had previous subjectspecific teacher-training. This provides strong evidence that there is an unmet need for opportunities to attend subject-specific teachers' training. Many of the attendees gave feedback with the highest score out of five, indicating that they found the event 'very valuable'.

\section{Educational Implications}

Our case study on providing subject-specific teachers' training may be a valuable model, not only for cancer biology, but for many other subjects as well. This concept of subject-specific training is not only a current topic of discussion but also builds upon historical comments in the literature. For example, Todd (2016) performed a SWOT analysis of the importance of subject-specific training for History. He was responding to a survey carried out by the Historical Association that concluded that very little History-specific training is provided in continuing professional development. Todd concluded that this type of training rekindles passion and creativity in teachers. He references the Carter review 2015 of ITT, which highlights the importance of subject-specific training for subject-specific knowledge and pedagogy. He also supports his discussion with a quotation from Jerome Bruner (1960): "It takes no elaborate research to know that communicating knowledge depends in enormous measure upon one's mastery of the knowledge to be communicated."

Opportunities for sharing of best practice in one's field always promise to support subjectspecific pedagogical skill development. Discussions may also identify new motivational forces for learning.

Subject-specific networking provides many valuable opportunities for enriching crossinstitution education. We have evidence that the networking from this workshop resulted in fruitful collaborations. Early-career educators were invited to other universities as visiting lecturers, and other members were invited to act as external examiners. Possible research collaborations are being explored. 
We reflected on the view of Rowland et al., (1998) that information technologies should be explored, but not simply as the addition of 'teaching skills' to the repertoire of the academic, as if such skills existed in a vacuum divorced from the subject matter which they are intended to communicate. Thus, for our workshop, we produced a list of specific information technology resources and sample applications that may be useful for teaching cancer biology. As evidenced by feedback comments, this became a resource for immediate use. A similar IT teaching resource could be produced for other subjects.

\section{Reference list}

Biggs, J. and Tang, C. (2011) Teaching for quality learning at university. $4^{\text {th }}$ edition. Maidenhead: SRHE and Open University Press.

Bruner, J. (1960) The Process of Education. Cambridge, MA: Harvard University Press.

Coe, R., Aloisi, C., Higgins, S. and Major, L.E. (2014) 'What makes great teaching? Review of the underpinning research.' The Sutton Trust Report. Available at:

https://www.suttontrust.com/wp-content/uploads/2014/10/What-Makes-Great-TeachingREPORT.pdf (Accessed: May 2016).

Crompton, H. (2013) Handbook of mobile learning. New York: Routledge, 41-52.

Erikson, C., Salsberg, E., Forte, G., Bruinooge, S. and Goldstein, M. (2007) 'Future supply and demand for oncologists: challenges to assuring access to oncology services.' Journal of Oncology Practice, 3(2), 79-86. Available at:

www.ncbi.nlm.nih.gov/pubmed/20859376https://www.ncbi.nlm.nih.gov/pubmed/20859376 (Accessed: October 2016).

Flint, A. (2015) 'Students and staff as partners in innovation and change.' The Journal of Educational Innovation, Partnership and Change, (1)1. Available at:

https://journals.gre.ac.uk/index.php/studentchangeagents/article/view/218 (Accessed: 01 April 201묘).

Fordham, M. (2014) '90\% of teacher training should be subject-specific.' Clio et etcetera. Available at: https://clioetcetera.com/2014/08/28/90-of-teacher-training-should-be-subjectspecific/ (Accessed: June 2016).

Fry, H., Ketteridge, S. and Marshall, S. (2008) A handbook for teaching and learning in higher education. $3^{\text {rd }}$ edition. New York: Routledge.

Gaffan, J., Dacre, J. and Jones, A. (2006) ‘Educating Undergraduate Medical Students About Oncology: A Literature Review.' Journal of Clinical Oncology, 24:12, 1932-1939. Available at: https://www.ncbi.nlm.nih.gov/pubmed/16622269 (Accessed 7 September 2016).

General Medical Council (2016) Available at: http://www.gmcuk.org/Promoting excellence standards for medical education and training 0715.pdf 61 939165.pdf (Accessed: September 2017). 
Hanahan, D. and Weinberg, R.A. (2011) 'Hallmarks of cancer: the next generation.' Cell Press, 144, 646-674. Available at: https://www.cell.com/cell/pdf/S0092-8674(11)00127-9.pdf (Accessed: January 2012).

Kolb, D.A. (1984) Experiential learning: experience as the source of learning and development. Englewood Cliffs: Prentice Hall. Available at : https://www.researchgate.net/publication/235701029 Experiential Learning Experience As The Source Of Learning And Development (Accessed July 2017).

KKoole, M. (2009) 'A Model for Framing Mobile Learning.' In: Ally, M. (ed.), Mobile Learning: Transforming the Delivery of Education and Training. Calgary: AU Press, Chapter 2.

Laurillard, D. (2012) Teaching as a Design Science. London: Routledge.

Neville, A.J. (2009) 'Problem-based learning and medical education forty years on. A review of its effects on knowledge and clinical performance.' Medical Principles and Practice, 18(1), $1-9$.

Race, P. (2009) Designing assessment to improve Physical Sciences learning. York: Higher Education Academy.

Pecorino, L. (2016) The Molecular Biology of Cancer. $4^{\text {th }}$ edition. Oxford: Oxford University Press.

Ritchie, L. (2015) Fostering self-efficacy in Higher Education students. Basingstoke: Palgrave Teaching and Learning.

Rowland, S., Byron, C., Furedi, F., Padfield, N. and Smyth, T. (1998) 'Turning academics into teachers?' Teaching in Higher Education, 3, 133-141. Available at: www.tandfonline.com/doi/abs/10.1080/1356215980030201 (Accessed: September, 2016).

Stock, P. (2016) 'What makes great training? 10 ideas for developing subject knowledge and pedagogy.' Available at: https://joeybagstock.wordpress.com/2016/01/10/what-makes-greattraining-10-ideas-for-developing-subject-knowledge-and-pedagogy/ (Accessed: April 2017).

Todd, J.J. (2016) 'The importance of subject specific training.' Teaching History, 162.

Wagle, N., Emery, C., Berger, M.F., Davis, M.J., Sawyer, A., Pochanard, P., Kehoe, S.M., Johannessen, C.M., Macconaill, L.E., Hahn, W.C., Meyerson, M. and Garraway, L.A. (2011) 'Dissecting therapeutic resistance to RAF inhibition in melanoma by tumor genomic profiling.' Journal of Clinical Oncology,. 29,3085-3096. Available at : www.ncbi.nlm.nih.gov/pubmed/21383288 (Accessed: May 2015). 